$\operatorname{cocos}$ (1996), 11, 07 - 20

Printed in Sri Lanka

\title{
'PHOTOSYNTHETIC CHARACTERISTICS AND PRODUCTIVITY OF THE COCONUT PALM
}

\author{
C Jayasekara, N P A D Nainanayake \& K S Jayasekara*
}

Coconut Research Institute, Lunuwila, Sri Lanka

\begin{abstract}
Among the tree crops in the tropics the coconut palm occupies an important position as. a food, oil, and fibre crop. Productivity of crop species depends on the combined effect of their genetic constitution, climate, nutrition and other biotic factors. To increase the productivity of the coconut palm it is necessary to have a basic understanding of physiological processes such as assimilation of carbon and growth in relation to climatic factors.

In-situ photosynthetic measurement of coconut seedlings using Li-COR 6500 portable photosynthesis system revealed that their maximum photosynthetic capacity is attained at photosynthetic photon flux densities (PPFD) ranging from 1400-1700 $\mu$ moles photons $\mathrm{m}^{-2} \mathrm{~S}^{-1}$. The rate of apparent photosynthesis (A) of the coconut palm varies between 2-15 $\mu$ mol $\mathrm{CO}_{2} \mathrm{~m}^{-2} \mathrm{~S}^{-1}$ depending on leaf age, nutritional status .and climatic factors. The rate of leaf respiration was closely similar in young and older leaves ranging from -2 to $-1 \mu \mathrm{mol} \mathrm{CO}_{2} \mathrm{~m}^{-2} \mathrm{~s}^{-1}$. The measured light-use efficiency of the coconut palm was found to be $1.2 \mathrm{~g} \mathrm{M}^{-1}$ and the conversion efficiency of solar energy was approximately $2.4 \%$.

Water deficit is the major constraint causing wide fluctuations in photosynthesis. Due to height of trees, the leaves in the canopy are exposed to a high wind velocity as well as water and thermal stresses. As a result, under soil water deficit conditions coconut palms reduce excessive water loss and gaseous exchange by mid-day closure of stomata and maintain stomatal conductance at a lower level. However, the rate of apparent photosynthesis and the ratio of intercellular to ambient partial pressure of $\mathrm{CO}_{2}\left(\mathrm{P}_{1} / \mathrm{P}_{2}\right)$ are not decreased proportionately with the stomatal conductance.
\end{abstract}

1 Paper presented at the International Symposium on Plantation Crops (PLACROSYM XI) 30 November - 3 December 1994, Calicut, Kerala, India.

* Present Address - Coconut Cultivation Board, 55/75, Vauxhall Lane, Colombo 02. 


\section{INTRODUCTION}

Many factors limit crop productivity. In order to determine the influence of those factors, it is useful to have an estimate of potential productivity. The potential dry matter production of coconut (Cocos nucifera L.) vary from $20 \mathrm{tha}^{-1} \mathrm{y}^{-1}$ to $50 \mathrm{t} \mathrm{ha}$ $y^{-1}$ (Corley, 1985; Foale, 1992). It should be emphasised that in economically important crops, the productivity is discussed on the basis of the proportion of dry matter available as economic yield. The highest recorded economic yield of coconut in terms of copra is about $6 \mathrm{tha}^{-1} \mathrm{y}^{-1}$, even though the theoretical potential yield is about $12 \mathrm{t} \mathrm{ha}^{-1} \mathrm{y}^{-1}$. Photosynthesis is the most important process in plants where solar energy is converted to utilizable chemical energy. Other life forms depend on this chemical energy. The economic yield of a crop, depends on the solar radiation intercepted, conversion efficiency of intercepted solar radiation into chemical energy or dry matter, and the efficient partitioning of assimilated dry matter between vegetative and harvestable parts of the plant. The highest conversion efficiency of photosynthetically active radiation (PAR) into dry matter in coconut has been estimated as 1.2 to $1.4 \mathrm{~g} \mathrm{MJ}^{-1}$ (Corley, 1983; Jayasekara, 1992). This estimated efficiency of conversion of PAR in coconut plantations is found to be similar to the tropical rain forest species (Saldrarriaga and Luxmoore, 1991), but lower than many $\mathrm{C}_{3}$ crops as their values generally falls in the order of $2.5-3.0 \mathrm{~g} \mathrm{MJ}^{-1}$.

Short wave solar radiation received in the wet humid tropics varies with altitude and season ranging from 1100 to $2200 \mu$ moles $\mathrm{m}^{-2} \mathrm{~s}^{-1}$. Light saturation of photosynthesis in many $C_{3}$ species takes place at $50 \%$ full sun light (Lowler, 1991). Further, photosynthetic productivity of plants is affected by the nutritional status, leaf age, water deficit, and many other environmental factors. In particular, changes in net assimilation of carbon at tissue or leaf level is a combined effect of changes taking place at organelle or cellular level and reflected as stomatal conductance and mesophyll capacity for photosynthesis.

\section{MATERIALS AND METHODS}

Two-year-old Tall $x$ Tall (CRIC 60) and Dwarf $x$ Tall (CRIC 65) seedlings grown in large cement pots under plant house conditions were used for light response studies.

Fifteen-year-old $D X T$ coconut palms growing at the Bandirippuwa Estate ( Low Country Intermediate Zone) and eight-year-old $D X T$ palms growing at the Thammanna Estate (Low Country Dry Zone) were selected for the study. Those palms were grown under generally recommended agronomic practices and have received recommended dosage of fertilizers based on foliar nutrient analysis. 


\section{Leaf Gas Exchange Measurements}

The rate of photosynthesis $(A)$, stomatal conductance $(g)$, leaf temperature $\left(T_{\nu}\right)$, intercellular $\mathrm{CO}_{2}$ concentration (Ci), rate of transpiration (E), and PAR were measured using a portable photosynthesis system (Li-COR 6500; Li-COR Inc, Nebraska, USA.). A leaf chamber having a volume of 0.251 and fitted with a viasala humidity sensor, thermocouple and a quantum sensor for measuring PAR in the range of $400-700 \mathrm{~nm}$ short wave radiation was. used for the study. The instrument operated at absolute mode and the air circulating through the system was passed through a non-dispersive infrared gas analyser (IRGA). The air in the system was dried by using a desiccant $\left[\mathrm{Mg}\left(\mathrm{ClO}_{4}\right)_{2}\right]$ before entering the IRGA as water vapour interferes with infra-red absorption band of carbon dioxide.

All the data were fed into a inbuilt computer through a data logger and rate of photosynthesis and other parameters were calculated. The boundary layer resistance (BLR) was taken as $0.12 \mathrm{~s} \mathrm{~cm}^{-1}$, (estimated based on the procedure given in the Manual), stomatal ratio $=0$ (as stomata are only on abaxial side of the coconut leaves, flow rate of air through the system was maintained at $9.5 \mathrm{~cm}^{-3} \mathrm{~s}^{-1}$. The measurement time was dependent on the time required to change $10 \mathrm{ppm}$ of $\mathrm{CO}_{2}$ from the system and the data being logged at 3 occasions at each change in $10 \mathrm{ppm}$ of $\mathrm{CO}_{2}$.

The dark respiration of leaves was measured by covering the leaf chamber with a black cloth. Leaflets were kept in dark inside the chamber for $20-30$ minutes to achieve maximum stomatal closure and gas exchange before making measurements.

The total leaf nitrogen content in leaf samples was determined by the micro kjeldhal digestion method and the chlorophyll A and B concentration in leaf samples were measured by the Arnon (1949) method.

\section{RESULTS}

Figure 1 shows the measured light responses on the rate of net photosynthesis of $D \times T$ seedlings. Middle leaflets of the second last open mature leaves of one and half years old seedlings were used for this study. Each data point represents the mean of 4 replicate plants. All the seedlings showed similar rate of net photosynthesis and maximum photosynthesis $\left(A_{\text {man }}\right)$ was reached when PAR was above $1400 \mu \mathrm{mol} \mathrm{m}^{-2} \mathrm{~s}^{-1}$. The photosynthesis responses showed no difference between $T X T$ and $D x T$ seedlings. The maximum average photosynthesis $\left(A_{\max }\right)$ obtained for $D \times T$ seedlings was $12.00 \pm \mu \mathrm{mol} \mathrm{CO}_{2} \mathrm{~m}^{-2} \mathrm{~s}^{-1}$ and for $T X T$ seedlings was $11.06 \pm 1.98 \mu \mathrm{mol} \mathrm{CO} \mathrm{m}^{-2} \mathrm{~s}^{-1}$. The apparent quantum yield at low light intensities (linear part of the response curve) was found to be $0.027 \mathrm{~mol} \mathrm{CO}{ }_{2}(\mathrm{~mol}$ photons) $^{-1}$ for both types of seedlings (Figure not presented for $T X T$ seedlings). 
The light compensation point for $D X T$ seedlings was $17 \mu \mathrm{mol} \mathrm{m}^{-2} \mathrm{~s}^{-1}$ and dark respiration rate was $-1.17 \mu \mathrm{mol} \mathrm{CO} \mathrm{m}^{-2} \mathrm{~s}^{-1}$. Whereas in $\mathrm{T} \times \mathrm{T}$ seedlings, the light compensation point was $36.4 \mu \mathrm{mol}$ of $\mathrm{CO}_{2} \mathrm{~m}^{-2} \mathrm{~s}^{-1}$ and dark respiration rate was $1.46 \mu \mathrm{mol} \mathrm{CO} \mathrm{m}^{-2} \mathrm{~s}^{-1}$.

The rate of photosynthesis in different leaf ranks, chlorophyll concentration are presented in Figure 2. There was no significant effect of leaf age on the rate of apparent photosynthesis between 3 months and 1 year (between leaf rank 3 and 14). However, there was a significant decline in net photosynthesis in older leaves between leaf rank 14 and 32 without significant change in chlorophyll concentration. The dark respiration of leaves decreased slightly with increasing age, but the variation was maintained within a narrow range between young and old leaves as shown in Figure 3. In mature leaves, it appears that the rate of net photosynthesis was either equivalent or less than the rate of dark respiration, suggesting that their assimilated carbon may be just sufficient for maintenance respiration.

The relationship between total leaf nitrogen content (as a percentage) and the leaf age is shown in Figure 4. The total leaf nitrogen increased significantly with increasing age of the immature leaves. Young tender leaves had very low levels of nitrogen. The total nitrogen content in young leaves which have been produced within the first year (leaf rank $4-13$ ) was maintained at a high level and then tends to decline significantly with increasing age (leaf rank 14-32). Gradual decline in leaf total nitrogen content with age, simply explains the reduced photosynthetic capacity of older leaves.

Figure 5 represents the seasonal variation in mean total canopy photosynthesis of fifteen-year-old two $D \times T$ hybrid coconut palms and mean annual rainfall. The wide fluctuations in total canopy net photosynthesis during the year coincide with the rainfall pattern. The estimated conversion efficiency of intercepted PAR under the observed photosynthetic level varied between 0.4 to $1.4 \mathrm{~g} \mathrm{Mij}^{-1}$ and maximum efticiency of conversion of intercepted PAR into dry matter was about $2.4 \%$.

Daily variation in the rate of net photosynthesis, rate of transpiration, leaf conductance to gaseous exchange of eight- year-old bearing $D X T$ coconut palms at Thammanne Estate (Intermediate Dry Zone) during rainy and rain free periods are given in Figures 6. During the rainy period light saturated maximum rate of net photosynthesis $\left(A_{\max }\right)$ of $17 \mu \mathrm{mol} \mathrm{m}^{-2} \mathrm{~s}^{-1}$ was recorded at PAR incidence of $1500 \mu$ mol photons $\mathrm{m}^{-2} \mathrm{~s}^{-1}$ and $A_{\max }$ was not affected when leaf temperature $T_{1}$ was reached up to $38{ }^{\circ} \mathrm{C}$. During the rainy period inter-cellular partial pressure of $\mathrm{CO}_{2}\left(\mathrm{C}_{\mathrm{i}}\right)$ was maintained between $200-250 \mathrm{ppm}$ and the stomatal conductance was varied between $300-450 \mathrm{~m} \mathrm{~mol} \mathrm{~m}^{-2} \mathrm{~s}^{-1}$. During early hours of the day palms maintained high

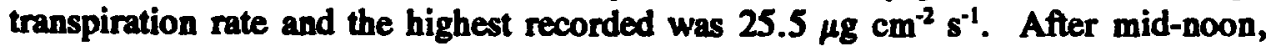
the rate of transpiration decreased gradually even though concomitant and gradual increase in stomatal conductance was observed. 


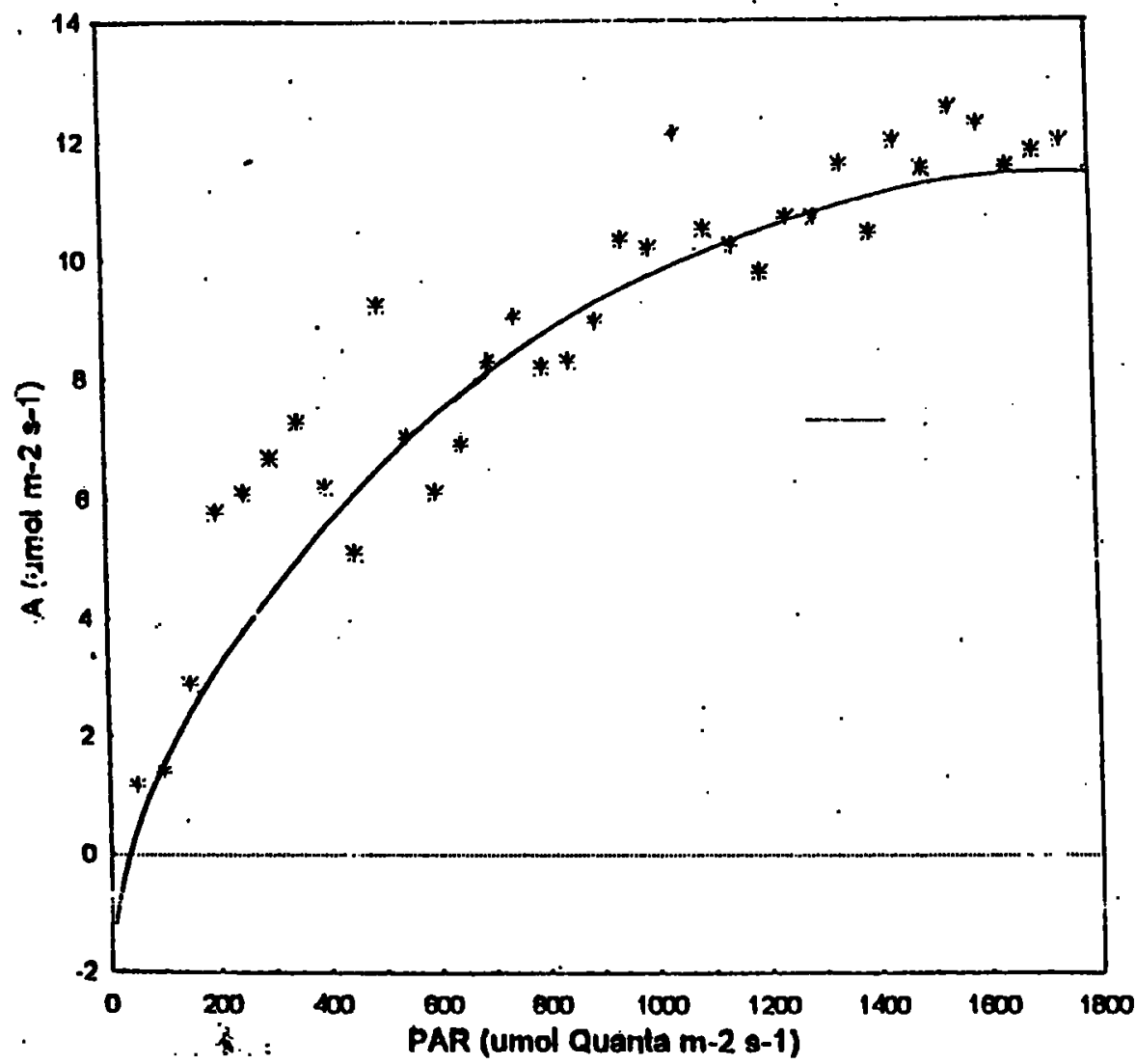

Figure 1 Net rate of photosynthesis (A) versus photosynthetically active radiation (PAR) of one and half years old $d \times t$ coconut seedlings $(n=4)$. Curve is fitted by eye. 


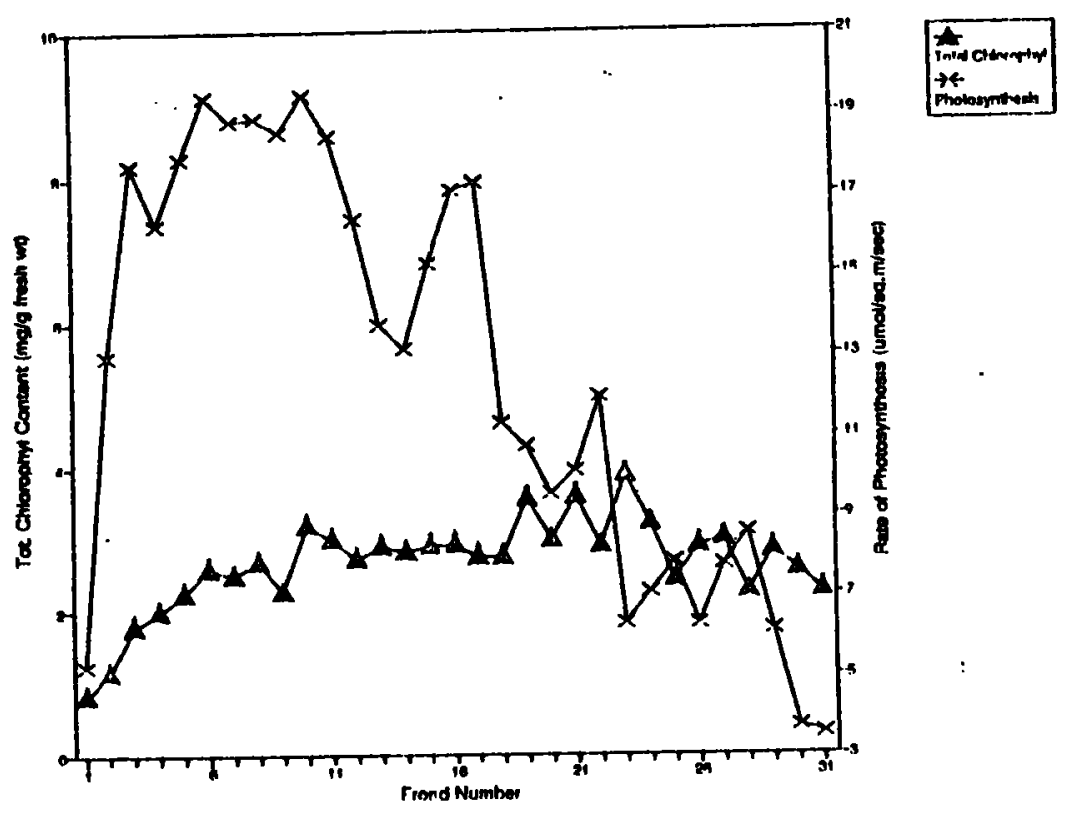

Figure 2 Variation in rate of photosynthesis and total Chlorophyll content with age of the fronds. 


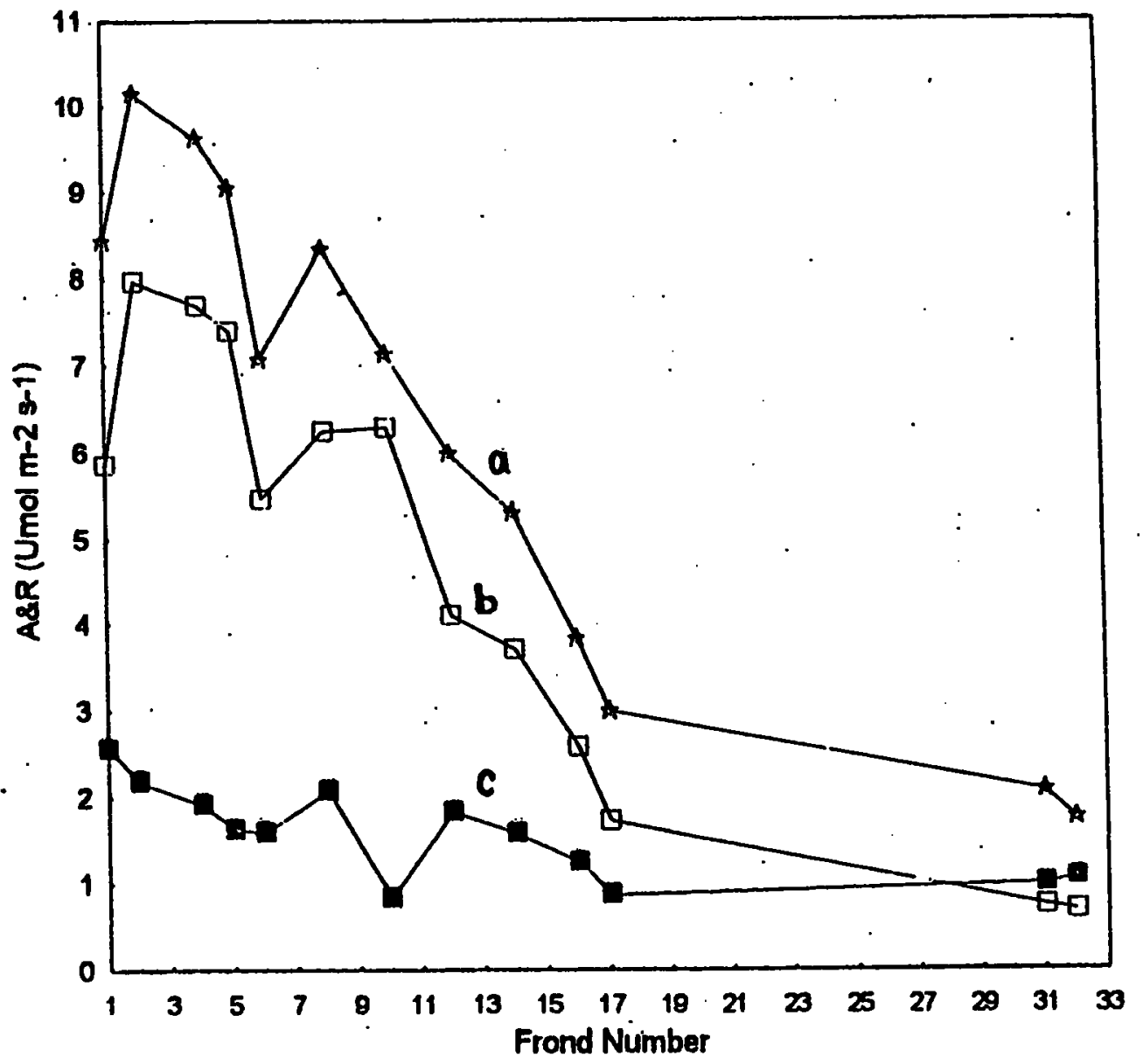

Figure 3 Variation in rate of gross photosynthesis (a) net photosynthesis (b) and dark respiration (c) in $d \times t$ coconut seedlings with leaf age. 


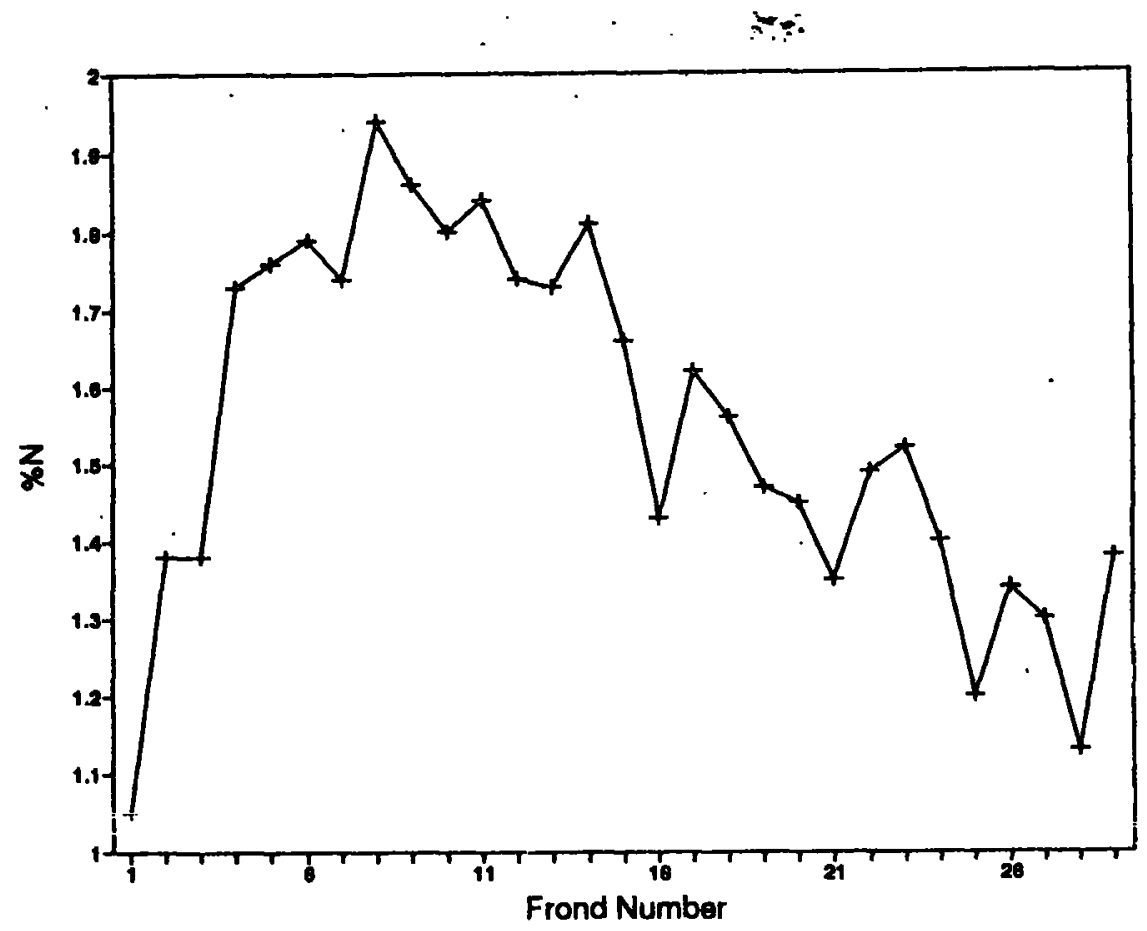

Figure 4 Percentage total nitrogen content of leaves on the dry mass basis versus frond number. Each data point is a mean of three DxT replicate palms. 


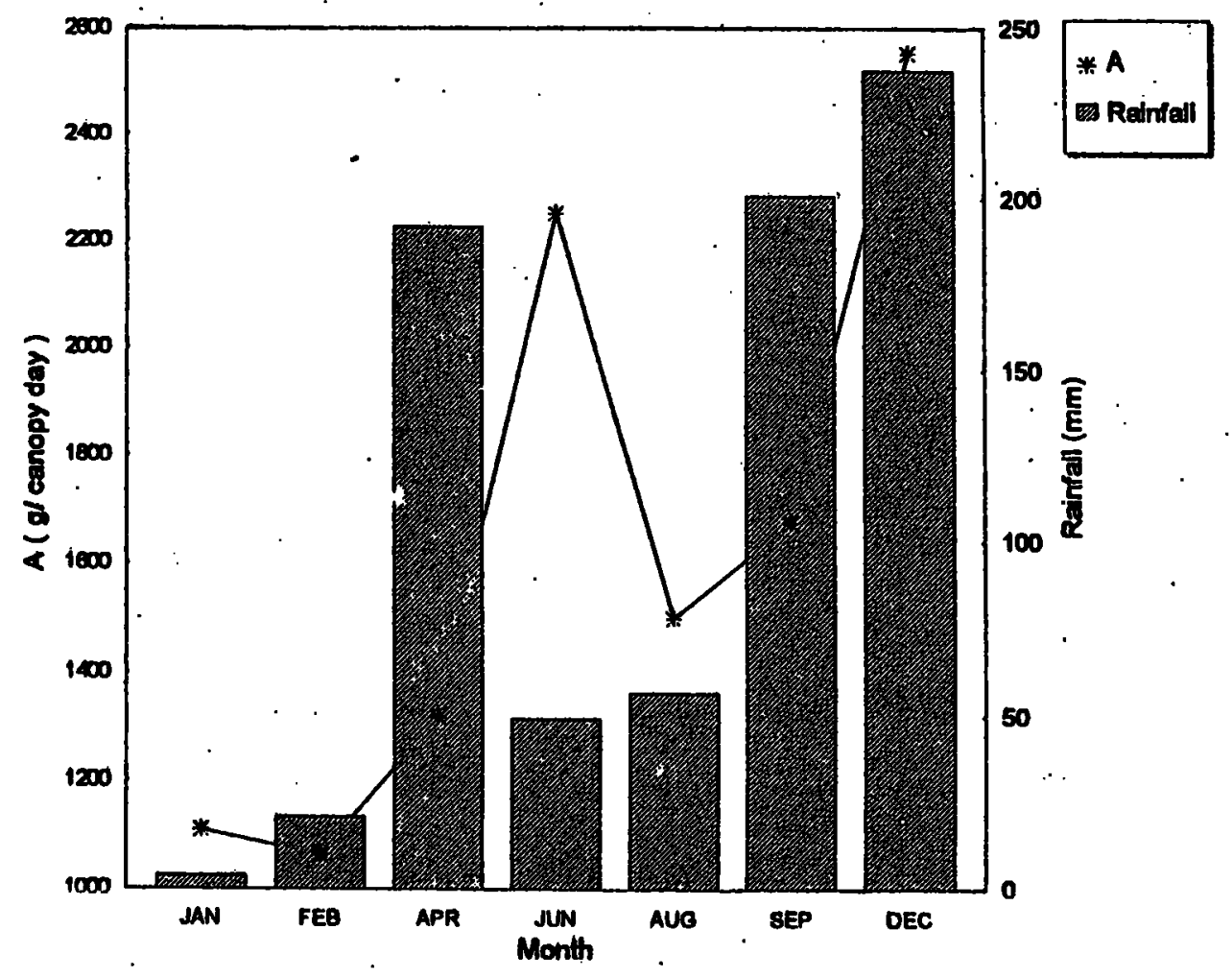

Figure 5 Estimated mean monthly net canopy photosynthesis of twelve year old $\mathrm{d} x \mathrm{t}$ hybrid coconut palms $(n=2)$. Vertical bars represent the average monthly rainfall. 

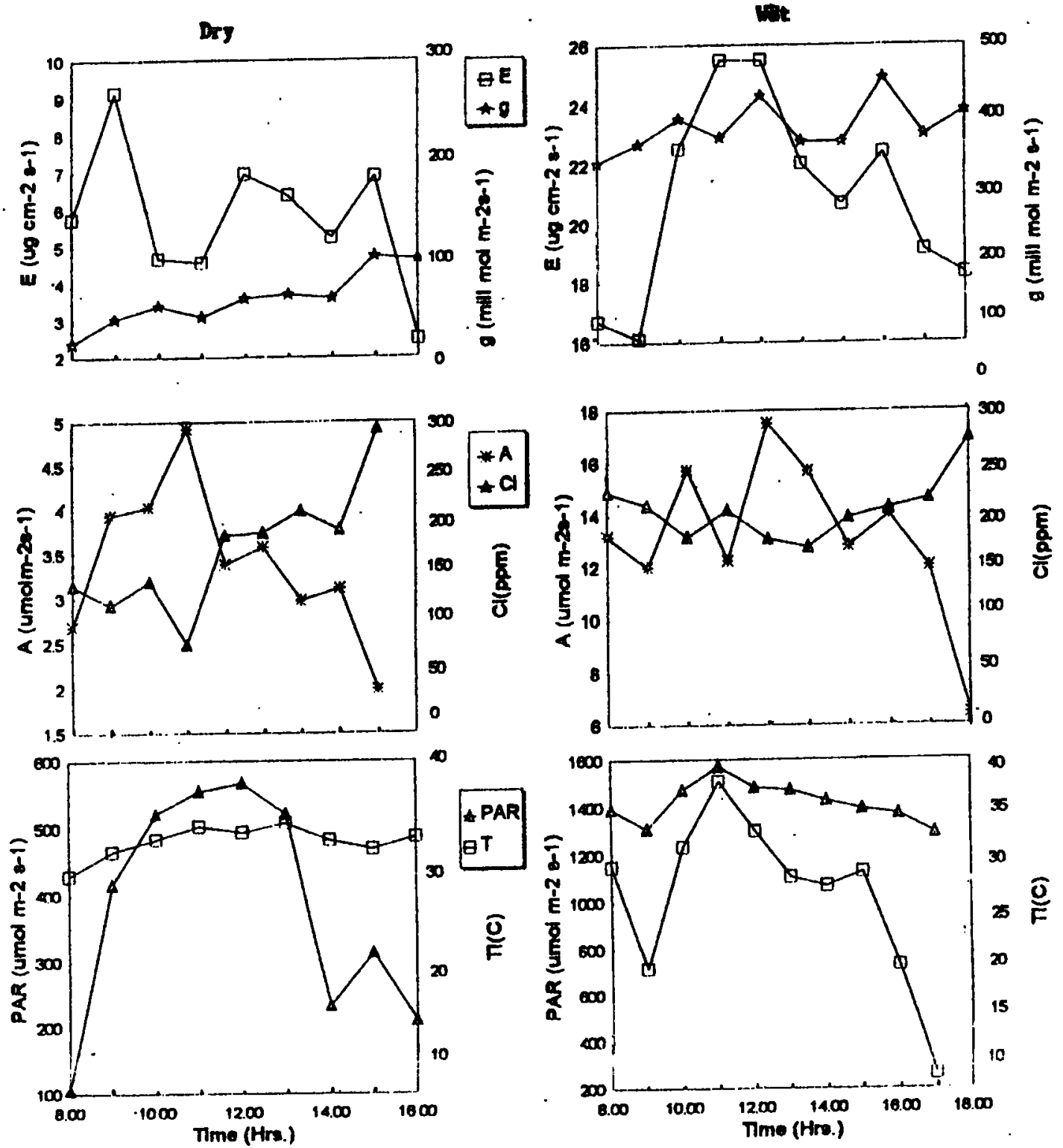

Figure 6 Daily variation in net photosynthesis (A) rate of transpiration (E), stomatal conductance $(\mathrm{g})$, intercellular partial pressure of $\mathrm{CO}_{2}\left(\mathrm{C}_{1}\right)$, leaf temperature (T1) and PAR during rain period (Wet) and rain free period (Dry). 
Several attempts were made to study the diurnal variation in net photosynthesis and transpiration of those same palms during the rain-free period. High temperature and light intensity that prevailed during the rain free period, were not conducive for obtaining continues measurements of rates of photosynthesis and transpiration due to closure of stomata by $10.00 \mathrm{am}$. The measured daily variation in the rate of net photosynthesis, transpiration, and leaf conductance during an over-casting day in the rain free period is given in Figure 6. Results revealed a three-fold decrease in the rate of net photosynthesis and transpiration during the rain free period when soil water deficit was increased and available soil watèr became limiting. Atmospheric temperature, and the intercepted solar radiation bad been high, even at early hours of the day under the above conditions. Thus, the palms exhibited very low rates of $\mathrm{CO}_{2}$ uptake and water vapour loss as a result of long-term drought. When the transpiration demand by the canopy cannot be met by the root system, the rate of transpiration was reduced by mid-day closure of stomata. Leaf stomatal conductance was slightly decreased during this period. Net photosynthesis was not affected to the extent that it affected the rate of transpiration during the period of mid-day closure of stomata. Thus, during short-term rain free periods, water-use efficiency of coconut palms could be increased by decreasing or controlling the rate of transpiration with slight or no decrease in net photosynthesis.

\section{DISCUSSION}

Intensity. of solar radiation arriving at the earth's surface in the wet tropics varies with latitude and season and is usually in the range of 11 to $22 \mathrm{MJ} \mathrm{m}^{-2} \mathrm{~d}^{-i}$ (1100 $2200 \mu \mathrm{mol} \mathrm{m}^{-2} \mathrm{~s}^{-1}$ ) (Monteith,1981). Light saturated maximum rate of net photosynthesis of coconut seedlings was reached at PAR interception around 1400 $\mu \mathrm{mol} \mathrm{m} \mathrm{m}^{-2} \mathrm{~s}^{-1}$ and which was about $60 \%$ of the intercepted PAR. Light saturation of photosynthesis in oil palm also takes place at similar levels (Dufrene and Saugier, 1993), but the rate of net photosynthesis of oil palm is higher $\left(23 \mu \mathrm{mol} \mathrm{m}^{-2} \mathrm{~s}^{-1}\right)$ than coconut. These observed light saturation levels are common to most of the $C_{3}$ plants. (Beadle et al., 1985).

The results indicate that the gradual decline in photosynthetic activity of coconut fronds after 12-14 months was accompanied by a decrease in the total nitrogen content while incident PAR also decreased due to the self shading effect from the upper canopy. The uppermost leaves in a coconut palm canopy are in an erectophile position and with increasing the leaf rank (mature/older leaves) lower leaves, approach a horizontal position and after leaf 14 the older leaves tend to reach downward position making a spherical shape crown. Warren Wilson (1960) suggested that canopies with nearly vertical orientation of uppermost leaves, with lower leaves approaching the horizontal position may effectively increase the photosynthetic efficiency by reducing excessive absorption per unit of leaf surface. Reduced photosynthetic activity in lower leaves could be due to low interception of solar radiation due to downwards orientation. Photosynthetic rate of plants is related to the 
nitrogen content in leaves (Field, 1983; Medina, 1984). The current study reveals that photosynthetic nitrogen-use efficiency (PNUE) of coconut fronds decline significantly with leaf age. The rate of net photosynthesis of plants depends both on stomatal conductance and mesophyll capacity for photosynthesis (Farquhar and Von Caemmerer, 1982). Mesophyll capacity depends, amongst other factors on the activities of ribulose 1-5 bisphosphate carboxylase oxygenase (Rubisco) and the capecity for ribulose bisphosphate (RuBP) regeneration (Von Caemmerer and Farquhar, 1984). RuBP carboxylase constitute about 20\% of the total leaf nitrogen, making it is the largest nitrogen containing component in a leaf (Evans and Seemann, 1984). Decline in leaf nitrogen content may contribute to the reduce mesophyll capacity for photosynthesis with leaf age.

The decrease in stomatal conductance and concurrent net photosynthesis during mid-day closure of stomata is a regulatory mechanism imposed in response to the short- term stress condition. The model proposed by Cowan (1982) suggests that variations in stomatal conductance in response to changes in environmental variables could be explained in terms of maximising assimilation and minimising transpiration. Based on his theory that total assimilation $A$ and total transpiration $E$ vary according to the equation,

$$
A-\frac{E}{\lambda}=\text { maximum }
$$

Where $\lambda$ is the benefit of carbon gain relative to the cost of water loss. Hence, under water deficit conditions $\lambda$ is adjusted to operate $A$ and $E$ in a way to achieve maximum benefit. When the stomata close inter-cellular partial pressure of $\mathrm{CO}_{2}\left(\mathrm{C}_{i}\right)$ may remain at the same level or increase slightly due to the changes in biochemical activities within the photosynthetic system which influences the release of $\mathrm{CO}_{2}$ by photo respiration. As a result, plants could maintain high photosynthetic rate during the period of closure of stomata despite its hindrance to photosynthetic $\mathrm{CO}_{2}$ uptake of leaves. During the period of stomatal closure maintenance of high internal $\mathrm{CO}_{2}$ partial pressure may help to avoid photo inhibition of the photosynthetic system as proposed by Powles and Critchly (1980).

\section{ACKNOWLEDGEMENT}

Authors wish to thank Ms Asoka de Saram, Mr L R S Silva and Mr R D N Premasiri, Technical Assistants of the Plant Physiology Division, Coconut Research Institute, for assisting field measurements and laboratory analyses.

\section{REFERENCES}

Arnon, D.I. (1949) Copper enzymes. Plant Physiol. 24, 1 : 3-5. 
Beadle, C.L., Long, S.P., Imbamba, S.K., Hall, D.O. and Olembo, R.J. (1985) Photosynthesis in Relation to Plant Production in Terrestrial Environments. Tycooly Publ., Oxford.

Caememerer, S. Von and Farquhar, G.D. (1984) Effects of partial defoliation changes of irradiance during growth, short term water stress and growth at enhanced $\mathrm{p}\left(\mathrm{CO}_{2}\right)$ on the photosynthetic capacity of leaves of phaseolus vulgaris L. Planta. 160: 320-324.

Corley, R.H.V (1983) Potential productivity of tropical perennial crops. Expt. Agric. 19: 217-237.

Corley, R.H.V (1985) Yield potential of plantation crops. In: Proc. 19th Colloq. Int. Potash Inst. Bangkok, Int. Potash Inst. Berne: 61-80.

Cowan, I.R. (1982) Regulation of water use in relation to carbon gain in higher plants. In Encyclopedia of Plant Physiology Volume 12 B. Physiological Plant Ecology II, Water Relations and Carbon assimilation: 589-613.

Dufrene E. and Saugier B. (1993) Gas exchange of oil palm in relation to light, vapour pressure deficit, temperature and leaf age, Oleagineux. 48: 8-9.

Evans, J.R. and Seeman, J.R. (1984) Differences between wheat genotypes in specific activity of Ribulose-1,5-bisphosphate carboxylase and the relationship to photosynthesis. Plant Physiol. 74: 759-765.

Farquhar, G.D. and Caemmerer, S. Von (1982) Modelling of photosynthetic response to environmental conditions. In: Encyclopedia of Plant Physiology N.S. Vol 12B. Physiological Plant ecology II. Water relations and carbon assimilation. pp 549588. Lange, O.L., Nobel, P.S., Osmand,C. B., and Zeigler, H. Eds. Spriger; Berlin, New York.

Field, C. (1983) Leaf age and seasonal effects on light, water and nitrogen use efficiency in a californian shrub. Oecologia 55: $348-355$.

Foale, M.A.(1992) Physiological basis for yield in coconut. In Advances in Coconut Research and Development. Eds: M.K. Nair, H.H. Khan, P. Gopalasundaram and E.V.V. Baskara Rao. Oxford \& I B H Publishing Co. PVT. Ltd. New Delhi, 209-218.

Jayasekara, C. (1992) Physiological studies on coconut. Transactions of Malaysian Soc. Plant Physiol. 3: 19-28. 
Johnson,C.B.(Edit),Butterworths,London, 23-39. Medina, E (1984) Nutrient balance and physiological precesses at the leaf level. In Physiological Ecology of Plants in the Wet Tropics. Medina, H.A. Mooney \& C. Vazquez -Yanes (Edit): 139153, Junk, The Hague.

Lawlor, D.W. (1987) Photosynthesis: Metabolism , control and physiology. Longmans, Harlow, pp. 262.

Monteith, J.L. (1981) Does light limit crop.production. In Physiological processes limiting Plant Productivity.

Powles, S.B., Critchley, C. (1980) Effect of light intensity during growth on photoinhibition of intact attached bean leaflets. Plant Physiol. 65, 1181-1187.

Saldarriagá, J.G. and Luxmoore R.J. (1991) Solar energy conversion efficiencies during succession of a tropical rain forest in Amazonia. J. Trop. Ecology. 7: 233-243.

Warren-Wilson,J.(1972) Control of crop processes. In A.R. Rees et al., Eds, Crop Processes in controlled Environments. Academic Press, London: 7-30. 